Article

\title{
Optimization, 3D-Numerical Validations and Preliminary Experimental Tests of a Wound Rotor Synchronous Machine ${ }^{\dagger}$
}

\author{
Huong Thao Le Luong ${ }^{1}$, Frédéric Messine ${ }^{1, * \mathbb{D}}$, Carole Hénaux ${ }^{1}$, Guilherme Bueno Mariani ${ }^{2} \mathbb{D}$, Nicolas Voyer $^{2} \mathbb{D}$, \\ Stefan Mollov ${ }^{2}$ and Dominique Harribey ${ }^{1}$
}

1 LAPLACE-CNRS, ENSEEIHT, Toulouse INP, University of Toulouse, 31000 Toulouse, France; leluonghuongthao89@gmail.com (H.T.L.L.); henaux@laplace.univ-tlse.fr (C.H.); Dominique.Harribey@laplace.univ-tlse.fr (D.H.)

2 MERCE, Mitsubishi Electric R\&D Centre Europe, 35700 Rennes, France; g.buenomariani@fr.merce.mee.com (G.B.M.); n.voyer@fr.merce.mee.com (N.V.); s.mollov@fr.merce.mee.com (S.M.)

* Correspondence: Frederic.Messine@laplace.univ-tlse.fr

$+\quad$ This paper is an extended version of our conference paper published in 2018 XIII International Conference on Electrical Machines (ICEM), Alexandroupoli, Greece, 3-6 September 2018; pp. 455-460.

Citation: Le Luong, H.T.; Messine, F.; Hénaux, C.; Mariani, G.B.; Voyer, N.; Mollov, S.; Harribey, D. Optimization, 3D-Numerical Validations and Preliminary Experimental Tests of a Wound Rotor Synchronous Machine. Energies 2021, 14, 8118. https:// doi.org/10.3390/en14238118

Academic Editor: Davide Astolfi

Received: 20 July 2021

Accepted: 22 November 2021

Published: 3 December 2021

Publisher's Note: MDPI stays neutral with regard to jurisdictional claims in published maps and institutional affiliations.

Copyright: (c) 2021 by the authors. Licensee MDPI, Basel, Switzerland. This article is an open access article distributed under the terms and conditions of the Creative Commons Attribution (CC BY) license (https:// creativecommons.org/licenses/by/ $4.0 /)$.

\begin{abstract}
In this paper, a complete methodology to design a modular brushless wound rotor synchronous machine is proposed. From a schedule of conditions and a chosen structure (with 7 phases, 7 slots and 6 poles), a non-linear and non-convex optimization problem is defined and solved using NOMAD (a derivative free local optimization code): the external volume is minimized under some constraints, which are the average torque equal to $5 \mathrm{Nm}$, the torque ripple less than $5 \%$, the efficiency greater than $94 \%$, and the surface temperature less than $85{ }^{\circ} \mathrm{C}$. The constraints have to be computed using 2D-finite element simulations in order to reduce the CPU-time consumption for each NOMAD iteration. Moreover, a relaxation of this optimization problem makes it possible to provide an efficient starting point for NOMAD. Thus, a good optimal design is obtained, and it is then validated by using 3D electromagnetic and thermic numerical methods. These numerical verifications show that, inside the end-winding, the leakage flux is high. This yields a lot of iron losses in this machine. Moreover, the surface and coil temperature differences between the 2D and 3D numerical approaches are discussed. Finally, the machine prototype is built following the optimal dimensions and a POKI-POKI ${ }^{\mathrm{TM}}$ assembly technology. Preliminary experimental tests are carried out, and the results are devoted to the comparison of measured and predicted 3D numerical results.
\end{abstract}

Keywords: wound rotor synchronous machine; optimization; 2D and 3D finite element analysis; 3D computational fluid dynamics; experimental test; optimal design

\section{Introduction}

Nowadays, compressors in Heating, Ventilation, and Air Conditioning (HVAC) application frequently use Permanent Magnet Synchronous Machine (PMSM) because of its high torque density and its high efficiency. However, the price of rare-earth magnet material increases sharply. Moreover, the quick depletion of rare-earth magnet resources is an issue since magnets are used more and more extensively. Therefore, other machines without magnets, and with high performances, have to be investigated to replace PMSM.

Wound Rotor Synchronous Machines (WRSMs) are widely used with a great efficiency and reliability for high power level electrical generation, see Figure 1. WRSMs own several advantages: a low cost, a wide field weakening region at high speed, and a significant improvement of the safety (this is due to the possibility to cancel the field current, which limits the risks of high voltages for high speed mode [1-6], and this corresponds to the requirements of HVAC applications). Nevertheless, the rotor windings cause Joule losses, and the heat is hard to evacuate. Moreover, the torque density of a WRSM is usually less 
than for a PMSM. In addition, the stator is powered by sinusoidal currents to generate an AC rotating field, while the rotor owns copper windings that are energized by a DC current to create a magnetic field. Hence, a mechanism is necessary in order to pass the current from the stationary part to the rotating part of the machine. The slip rings and the brushes can, thus, be necessary in order to supply the field current, and this yields maintenance problems.

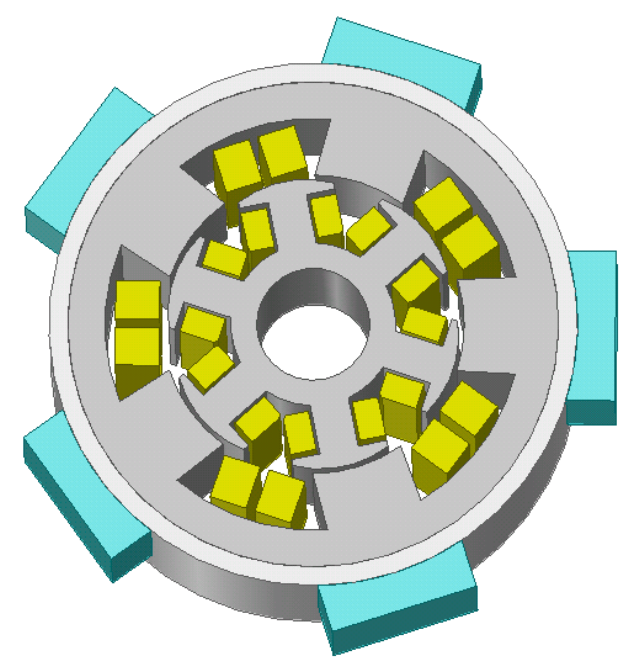

Figure 1. Single phase modular configuration.

In our study, modular brushless wound rotor synchronous machines (WRSM) which has several advantages such as low cost, high fault tolerance capability, and wide field weakening region are investigated. Indeed, the goal was to replace the PMSM inside its HVAC application by a WSRM. Therefore, the new WRSM should have the same or equivalent performances than the PMSM: the torque has to be equal to $5 \mathrm{Nm}$, the torque ripple less than $5 \%$, the efficiency has to be greater than $94 \%$. Moreover, because the power converters will be integrated around the WRSM, the temperature of the coils has to be less than $105^{\circ} \mathrm{C}$. This defines the main part of the schedule of conditions of our study. At the end, the purpose is also to minimize the global volume of such an efficient WRSM.

The use of a modular drive machine, as the one shown in Figure 1, increases the redundancy and the reliability of the system. Each phase of this modular structure is connected to a separate single-phase converter. Thus, each phase drive module is considered a single module and, therefore, each phase can operate independently of each other. These structures can reduce the effects on other phases in case of a fault on one phase. Note that, for this application, a rotary transformer is used for supplying the DC-current in the rotor winding.

An interesting concept to achieve greater modularity in the machine is the segmentation in the stator core. Our machine is built on the basis of the POKI-POKI ${ }^{\mathrm{TM}}$ assembly, as shown in Figure 2, where the stator core is not a massive entity as it is divided into individual segments. Each stator segment contains a tooth and a portion of the stator yoke. In addition, coils are wound for each segment. Then, the stator is assembled into a cylindrical shape and is pressed into a frame. The stator is then assembled and enclosed in a cylindrical frame. These types of stator have the following advantages: a fast (automatic) manufacturing of the winding, easy assembly and disassembly of each component, and easy replacement of a defective element, [7-9]. In addition, the fill factor of the slots can be increased, which reduces copper losses. 


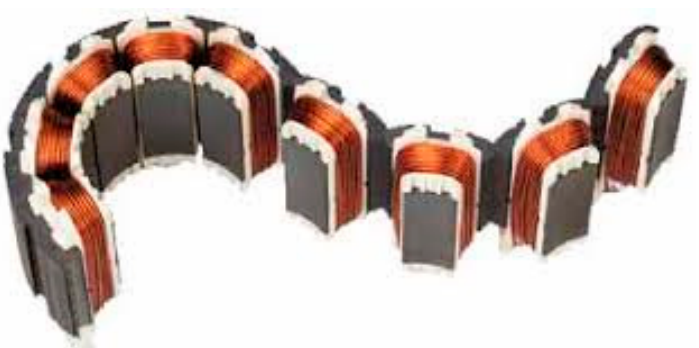

Figure 2. Modular structure of POKI-POKI ${ }^{\mathrm{TM}}$ machine [10].

In [11], using electromagnetic analysis, our choice about a 7-phases/7-slots/6-poles WRSM structure, with a concentrated fractional slot, winding without overlap is detailed; this WRSM was selected among a set of different machines. This choice was made based on the criteria of machine efficiency, torque density, and torque ripple. This WRSM was then compared to surface-mounted PMSM used in the market HVAC. The so-obtained results demonstrated that the modular brushless WRSM owns interesting features, with performances closely matching that of the PMSM. For details about this choice of this 7-phases/7-slots/6-poles WRSM structure, see [11].

With this selected WRSM structure, a heptagonal structure for the stator is chosen in this work. This allows one to increase the slot fill factor and generate more space in order to integrate the power converters on the machine housing. The 2D heptagonal structure of the WRSM is shown in Figure 3.

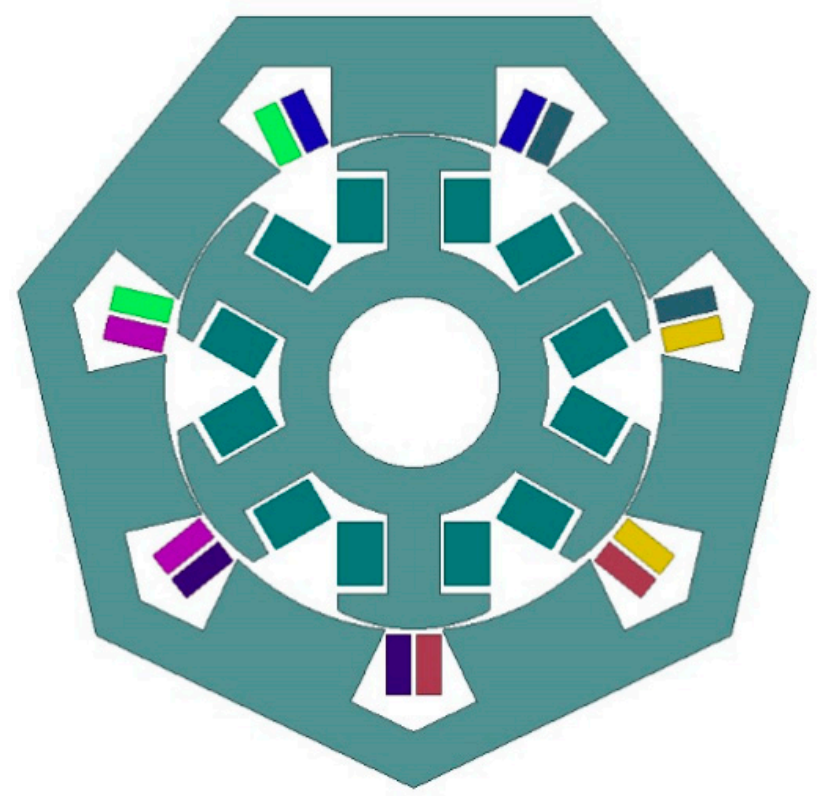

Figure 3. 2D structure of 7-phases/7-slots /6-poles heptagonal based WRSM.

In order to solve this design problem from the chosen heptagonal 7-phases/7-slots /6poles structure of a WRSM, a non-linear and non-convex optimization problem with constraints is formulated. This optimization problem has to be solved efficiently and quite rapidly by using NOMAD, which is a deterministic local derivative free software. Thus, 2D-Finite Elements (FE) simulations are used to compute all the constraints; the objective function is analytically known. Moreover, a relaxation of the optimization problem, associated with a multistart technique, is developed to provide an efficient starting point to initialize the first NOMAD iteration in order to solve the original problem. This optimization phase is presented in Section 2, where the best WRSM that we found so far is provided. The optimization problem does not strongly represent the schedule of conditions, so in Section 3, 3D-numerical simulations are performed using a 3D-magnetic model, which 
makes it possible to correct the optimized WRSM. Moreover, using a 3D-fluid dynamic model, the temperature of the WRSM is computed (mainly in the coils); this mainly summarizes results that we presented at the ICEM 2018 conference [5]. In Section 4, preliminary experimental tests of our first prototype are done, and this validates the 3D-numerical solutions found. In Section 5, we conclude.

\section{Optimization of a Heptagonal Based WRSM}

In order to formulate our optimization design problem, it is necessary to define which parameters are variables or fixed, the objective function, the inequality and equality constraints. The following optimization design problem tries to be as close as possible to the schedule of conditions presented in the introduction.

\subsection{Variables}

In this Subsection, we provide a description of all the parameters of design, which vary during the optimization process.

The width $B_{t}$ and the height $H_{t}$ of the tooth, the height $H_{y s}$ of the stator yoke, which represent the dimensions of the stator, are considered as optimization variables. All of these variables allowing the sizing of the stator are presented in Figure 4.

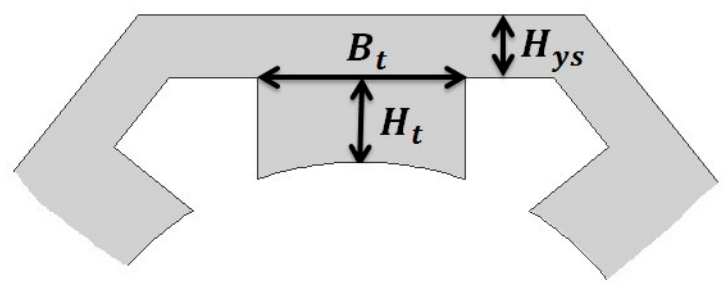

Figure 4. Dimension of heptagonal stator of the heptagonal based WRSM.

For the rotor part, the corresponding geometrical variables are shown in Figure 5: the height $H_{y r}$ of the rotor yoke, the diameter $D_{s h}$ of the shaft, and the dimensions of the rotor poles, such as the width $W_{s}$ and the height $H_{s}$ of the pole shoe, the width $W_{b}$ and the height $H_{b}$ of the pole body, the pole arc offset $O f f$ set which is usually used to modify the shape of the pole shoe; note that this parameter has a great impact on the value of the torque ripple.

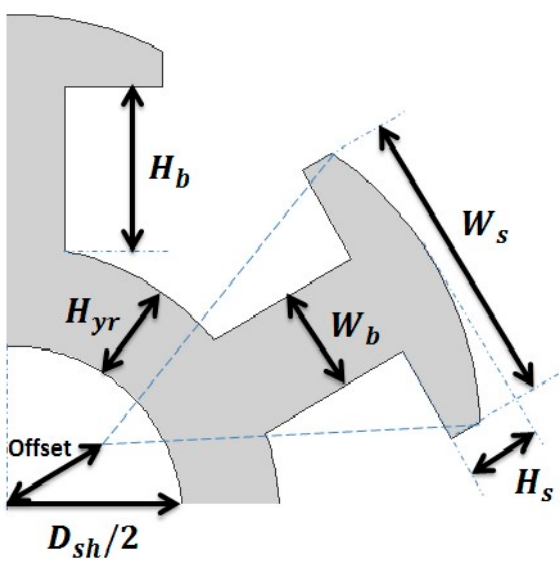

Figure 5. Dimension of salient pole rotor of the heptagonal based WRSM.

Furthermore, we have two variables to represent the current densities of the rotor and the stator windings. All of these optimization variables, including their respective bounds, are thus presented in Table 1. 
Table 1. Optimization Variables.

\begin{tabular}{cccc}
\hline Name & Symbol & Unit & Bounds on B \\
\hline Machine length & $L$ & $\mathrm{~mm}$ & $\mathrm{~B} 1=[20 ; 60]$ \\
Stator yoke height & $H_{y s}$ & $\mathrm{~mm}$ & $\mathrm{~B} 2=[05 ; 20]$ \\
Tooth height & $H_{t}$ & $\mathrm{~mm}$ & $\mathrm{~B} 3=[08 ; 30]$ \\
Tooth width & $B_{t}$ & $\mathrm{~mm}$ & $\mathrm{~B} 4=[20 ; 50]$ \\
Rotor yoke height & $H_{y r}$ & $\mathrm{~mm}$ & $\mathrm{~B} 5=[05 ; 20]$ \\
Pole shoe height & $H_{s}$ & $\mathrm{~mm}$ & $\mathrm{~B} 6=[03 ; 20]$ \\
Pole shoe width & $W_{s}$ & $\mathrm{~mm}$ & $\mathrm{~B} 7=[20 ; 60]$ \\
Pole body height & $H_{b}$ & $\mathrm{~mm}$ & $\mathrm{~B} 8=[10 ; 35]$ \\
Pole body width & $W_{b}$ & $\mathrm{~mm}$ & $\mathrm{~B} 9=[10 ; 30]$ \\
Pole arc offset & $O f f s e t$ & $\mathrm{~mm}$ & $\mathrm{~B} 10=[20 ; 90]$ \\
Shaft diameter & $D_{\text {sh }}$ & $\mathrm{mm}$ & $\mathrm{B} 11=[0 ; 30]$ \\
Armature current density & $J_{\text {cus }}$ & $A / \mathrm{mm}^{2}$ & $\mathrm{~B} 12=[0 ; 6]$ \\
Field current density & $J_{\text {cusr }}$ & $A / \mathrm{mm}^{2}$ & $\mathrm{~B} 13=[0 ; 4]$ \\
\hline
\end{tabular}

\subsection{Objective Function}

The objective function, coming from the schedule of conditions and from the choice of a heptagonal structure (see Figure 3), is the external volume of the machine, and it is constituted by the area of a regular heptagon $7 \times\left(\frac{D_{h}}{2}\right)^{2} \times \tan \left(\frac{\pi}{7}\right)$, where $\frac{D_{h}}{2}$ is the apothem (radius of the inscribed circle), multiplied by the length of the machine including the end-winding $L+h_{e w}$ :

$$
V_{\text {ext_ew }}^{h}=7 \times\left(\frac{D_{h}}{2}\right)^{2} \times \tan \left(\frac{\pi}{7}\right) \times\left(L+h_{\text {ew }}\right),
$$

where $h_{e w}$ is the axial height of one side end-winding and $D_{h}$ is the double of the apothem of the regular heptagon. They are calculated as follows:

$$
\begin{gathered}
V_{\text {ext_ew }}^{h}=7 \times\left(\frac{D_{h}}{2}\right)^{2} \times \tan \left(\frac{\pi}{7}\right) \times\left(L+h_{\text {ew }}\right), \\
D_{h}=D_{r}+2 \times e+2 \times H_{t}+2 \times H_{y s},
\end{gathered}
$$

where $B_{s 1}$ and $B_{s 2}$ are respectively the largest and smallest widths of the stator slot and $D_{r}$ is the diameter of the rotor and it is defined by:

$$
D_{r}=D_{s h}+2 \times H_{y r}+2 \times H_{b}+2 \times H_{s}
$$

\subsection{Inequality and Equality Constraints}

From the schedule of conditions presented in the introduction, the constraints are provided in this subsection. The purpose is to respect, at the best, the schedule of conditions with an efficient numerical way to compute the constraints in order to use optimization codes. Thus, using a 2D-Finite Element (FE) software, the values of: - the average torque $T_{e m}$, - the minimal torque $T_{\min }$, - the maximal torque $T_{\max }$, - the mechanical power $P_{\text {out }}$, - the total copper losses of the windings $P_{\text {copper }}$, - the total iron losses of the lamination cores $P_{\text {iron }}$, and -the total losses of the machine $P_{\text {total }}$ are computed. From these values, the torque ripple, the efficiency of the motor, and the surface temperature are derived as follows:

- The torque ripple $\Delta T$ is defined by:

$$
\Delta T=\left(T_{\max }-T_{\min }\right) / T_{\text {em }},
$$


- The efficiency $\eta$ of the motor is determined by:

$$
\eta=\frac{P_{\text {out }}}{\left(P_{\text {out }}+P_{\text {copper }}+P_{\text {iron }}\right)},
$$

It is worth noting that the design of electrical machines using numerical simulations has been widely developed because these simulations make it possible to consider both saturation and complicated geometry [12,13].

For this application, as explained in the schedule of conditions, an upper limit on the maximal temperature of the coils is set to $105^{\circ} \mathrm{C}$. At this step, it was not possible to directly take into account this constraint because we have no efficient and quick way to compute it, so we choose to impose the surface temperature of the machine to be less than $85^{\circ} \mathrm{C}$ by using the following equation:

$$
T_{s}=T_{a m b}+\Delta T^{\circ}=T_{a m b}+P_{\text {total }} \times R_{\theta},
$$

where $T_{S}$ is the surface temperature of the machine, $T_{a m b}$ is the ambiance temperature $\left(=25^{\circ} \mathrm{C}\right), P_{\text {total }}$ is the total losses and coefficient $R_{\theta}$ represents the thermal resistance for the convection and it is defined by:

$$
R_{\theta}=1 / h S,
$$

with $h$ the convection heat transfer coefficient, $S$ the complete cylindrical surface area of the frame.

For natural convection, the value of the convection heat transfer coefficient was presented in [12]. This value is normally in the interval $[10 ; 30] \mathrm{W} / \mathrm{m}^{2} \mathrm{~K}$. In this study, the convection heat transfer coefficient is fixed to $h=20 \mathrm{~W} / \mathrm{m}^{2} \mathrm{~K}$.

The constraints are: the average torque is fixed to $5 \mathrm{~N} . \mathrm{m}$, the torque ripple is limited by $5 \%$ for realistic operation, the machine efficiency should be higher than $94 \%$, and the surface temperature has to be lower than $85^{\circ} \mathrm{C}$ for ensuring the integration of the power converters without cooling system. These are closest as possible to the required industrial specifications for our application. The list of constraints is summarized in Table 2.

Table 2. Optimization Constraints.

\begin{tabular}{ccc}
\hline Symbol & Name & Relation \\
\hline$C_{1}$ & Average torque & $T_{e m}=5 \mathrm{Nm}$ \\
$C_{2}$ & Torque ripple & $\Delta T \leq 5 \%$ \\
$C_{3}$ & Efficiency & $\eta \geq 94 \%$ \\
$C_{4}$ & Surface temperature & $T_{s} \leq 85^{\circ} \mathrm{C}$ \\
\hline
\end{tabular}

The accuracy about the numerical values computed using 2D-FE simulations, mainly depends on the number of rotor positions; note that four positions are sufficient to provide good values for $T_{e m}, \Delta T, P_{\text {copper }}$, and $P_{\text {out }}$ but for computing efficiently $T_{s}$ and using the ANSYS-Maxwell software 120 rotor positions are necessary (mainly for computing efficiently the iron losses).

Some obvious geometrical constraints are used, but they are not given in this paper. Moreover, no mechanical constraint is considered because this machine will be used at low speed (less than $7000 \mathrm{rpm}$ ), and the obtained optimal solution appears to be not so sensitive to some mechanical stresses. 


\subsection{Optimization Problem}

The optimization problem of design addressed in this paper is the following:

$$
(\mathcal{P})\left\{\begin{array}{c}
\min V_{\text {ext_ew }}^{h} \\
x \in B^{13} \\
u c: \\
T_{e m}^{120 p}=5 \mathrm{Nm} \\
\Delta T^{120 p} \leq 5 \% \\
\eta^{120 p} \geq 94 \% \\
T_{s}^{120 p} \leq 85^{\circ} \mathrm{C}
\end{array}\right.
$$

All the constraints are computed using 2D-FE simulation by using ANSY-Maxwell software. Note that 120 rotor positions have to be done in order to obtain good surface temperature; remark that 20 min are necessary to compute just one 2D-FE simulation (with 120 rotor positions ad a large mesh size).

\subsection{Optimization Algorithm: NOMAD}

In this subsection, we summarize the principle of NOMAD software, which is a deterministic derivative free optimization solver and which is efficiently used in this study to solve our design problem $(\mathcal{P})$, see $[14,15]$.

NOMAD code based on Mesh Adaptive Direct Search (MADS) algorithm, which is available in the Matlab Toolbox OptiTool, can solve non-linear and non-convex constrained problems. It is well suited to solve black-box optimization problems whereby the function or/and the constraints are computed via a numerical code. Indeed, MADS is a kind of local direct search methods $[15,16]$. NOMAD includes a search step and a poll step. Trial points are generated at each search step on a mesh grid by using a mesh size parameter. Then, random points are taken at the poll step among the mesh points in the frame with a poll size parameter. Considering an iteration $\mathrm{k}$, the frame center is the center of a mesh. When a new point which improve the design is located in the neighborhood, it becomes the new frame center. A new mesh is generated from this new frame center and its corresponding mesh size is controlled in order to obtain a solution. These mesh sizes will be increased for successful searches and respectively decreased. When a small tolerance value is reached for the mesh size, an optimal solution is so obtained and thus, NOMAD stops; it was proven that NOMAD guarantees at least local optima, [15].

Even if NOMAD solver is already used to solve many industrial optimization problems, out of our knowledge, it was never used to optimize the design of electrical machines. This study shows the great interest to use NOMAD solver for these kinds of design applications. NOMAD code was compared to code based on gradient descent steps for two numerical design problems associated with FE analysis, and the results showed that NOMAD code gives better solutions for designing WRSMs, see [17].

\subsection{Starting Points}

NOMAD solver is able to directly solve problem $(\mathcal{P})$. However, because NOMAD is a local solver, and because problem $(\mathcal{P})$ owns many local minima, the so-obtained optimal solution strongly depends on the starting point given to initialize the NOMAD first iteration. In that case, the idea to solve problem $(\mathcal{P})$ using plenty of randomly generated starting points is not suitable because solving problem $(\mathcal{P})$ is too expensive in CPU-times: about 5 days. Thus, in order to reduce the CPU-time and to explore a large part of the research domain using plenty of starting points, a relaxation of the optimization problem $(\mathcal{P})$ is proposed. The purpose is to find the best possible local solution of this relaxed problem and to take it as a starting point to solve problem $(\mathcal{P})$. In order to reduce the computational time, the candidate machine designs are only analyzed at several rotor positions (here, only four rotor positions) to provide an efficient average torque $T_{e m}^{4 P}$ (error $\leq 1 \%$ ) with the simplified torque ripple $\Delta T^{4 P} \leq \Delta T^{120 P} \leq 5 \%$. Additionally, since the copper losses can 
be computed analytically, and since the machine temperature is linked to the loss density, the total copper losses are used in order to replace the efficiency and the temperature constraints. This copper losses compared to the mechanical power are limited to 3\%. The relaxed problem is defined by:

$$
(\mathcal{P})\left\{\begin{array}{l}
\min V_{\text {ext_ew }}^{h} \\
x \in B^{13} \\
u c .: \\
T_{\text {em }}^{4 P}=5 \mathrm{Nm} \\
\Delta T^{4 P} \leq 5 \% \\
P_{\text {copper }}{ }^{4 P} / P_{\text {out }} 4 P \leq 3 \%
\end{array}\right.
$$

The best local minima (found by using a multistart method) of the relaxed problem $\left(\mathcal{P}_{\boldsymbol{R}}\right)$ is considered as a starting point for our optimization problem $(\mathcal{P})$. This makes the optimization method search better for the whole domain of variables.

\subsection{Optimization Results}

First, note that, in order to solve those optimization problems $(\mathcal{P})$ and $\left(\mathcal{P}_{R}\right)$, we implement a MatLab code in order to define the objective function and all the constraints. In those MatLab subprograms, indirect links between NOMAD optimization solver and ANSYS-Maxwell 2D-FE simulations code are done.

Thus, the obtained optimal values of the optimized variables and the performance of the machine are represented in Tables 3 and 4. Note that the optimal WRSM is the best local optimum that we found so far by using NOMAD (linked to 2D-FE ANSYS-Maxwell); in order to solve $(\mathcal{P}), 5$ days of computations on a PC-server with 16 processors $(2.6 \mathrm{GHz}$ and $128 \mathrm{~GB}$ ) was needed to obtain a local solution. Moreover, in the previous phase, which consists of solving the relaxed problem $\left(\mathcal{P}_{\boldsymbol{R}}\right)$, a few distinct and randomly generated starting points were used. In column 2 of Table 3 , only the best local minimum is provided from a set obtained using the multistart method.

Table 3. Optimized Variables.

\begin{tabular}{cccc}
\hline Variable & $\begin{array}{c}\left(\mathcal{P}_{\boldsymbol{R}}\right) \\
\text { Starting Point for }(\mathcal{P})\end{array}$ & $\begin{array}{c}(\mathcal{P}) \\
\text { Optimal Design }\end{array}$ & Unit \\
\hline Machine length & 39.92 & 31.62 & $\mathrm{~mm}$ \\
Stator yoke height & 9.33 & 13.95 & $\mathrm{~mm}$ \\
Tooth height & 13.21 & 18.38 & $\mathrm{~mm}$ \\
Tooth width & 30.82 & 45.46 & $\mathrm{~mm}$ \\
Rotor yoke height & 8.75 & 12.88 & $\mathrm{~mm}$ \\
Pole shoe height & 5.30 & 9.80 & $\mathrm{~mm}$ \\
Pole shoe width & 39.39 & 41.90 & $\mathrm{~mm}$ \\
Pole body height & 16.35 & 22.14 & $\mathrm{~mm}$ \\
Pole body width & 23.81 & 14.50 & $\mathrm{~mm}$ \\
Shaft diameter & 43.18 & 47.53 & $\mathrm{~mm}$ \\
Pole arc offset & 7.12 & 23.18 & $\mathrm{~mm}$ \\
Armature current density & 4.36 & 2.69 & $\mathrm{~A} / \mathrm{mm}^{2}$ \\
Field current density & 6.27 & 3.87 & \\
\hline
\end{tabular}

Table 4. Optimized machine performance.

\begin{tabular}{cccc}
\hline Performance & $\left(\mathcal{P}_{\boldsymbol{R}}\right)$ & $(\mathcal{P})$ & Unit \\
\hline Average torque & 4.99 & 4.9977 & $\mathrm{Nm}$ \\
Torque ripple & $3.35 \%$ & $3.51 \%$ & \\
Total losses & 223 & 162.46 & $\mathrm{~W}$ \\
Efficiency & $94.16 \%$ & $95.56 \%$ & \\
Temperature & 151.11 & 85 & ${ }^{\circ} \mathrm{C}$ \\
\hline
\end{tabular}


The minimal value of the external volume is $2.0542 \times 10^{6} \mathrm{~mm}^{3}$. This value includes the space of the end-winding. Note that, due to the constraint on the temperature, the optimal machine must be large enough in order to reduce the surface temperature of the frame.

\subsection{Optimization Methodology}

In conclusion, an optimization methodology is developed in order to find a very efficient design of a WRSM, which satisfies, as close as possible, the schedule of conditions. First, an optimization problem $(\mathcal{P})$ is defined, it is non-linear, non-convex, and thus, it owns many local minima. In [10], it was shown that NOMAD software is well adapted to find good local optima of problem $(\mathcal{P})$. Nevertheless, it needs about 5 days of computations to solve problem $(\mathcal{P})$, and the local solution strongly depends on the chosen starting point. Thus, our optimization methodology follows this strategy: (i) a relaxation $\left(\mathcal{P}_{R}\right)$ of problem $(\mathcal{P})$ is proposed (note that $\left(\mathcal{P}_{R}\right)$ can be solved by NOMAD in a few hours), (ii) randomly generated starting points are used to initialize the searches using NOMAD of local minima of $\left(\mathcal{P}_{R}\right)$ (this is, in fact, a multistart global optimization approach used to solve problem $\left(\mathcal{P}_{R}\right)$ ), (iii) the best local minima of $\left(\mathcal{P}_{R}\right)$ is selected to be a starting point for NOMAD to solve problem $(\mathcal{P})$. This methodology of optimization makes it possible to provide the best solution of design that we found so far (see Tables 3 and 4 ).

\section{3D Numerical Validations}

\subsection{Introduction}

The optimal solution obtained in the previous section (see Table 3) satisfies the schedule of conditions, depending on the way to define and to compute the constraints (see Section 2.3). The constraints of the optimization problem are computed via 2D-FE simulations, and the limit on the temperature of the coils are replaced by a limit on the surface temperature, so some 3D-numerical verifications have to be done. Firstly, 3Delectromagnetic simulations are performed on this optimized WRSM in order to check the values of the average torque, the torque ripple, the efficiency of the machine, and the surface temperature, computed using Equation (7). Secondly, a 3D-thermal analysis is done to compute the temperature in all points of the machine and to check, as requested by the schedule of conditions, if the temperature in the coils is less than $105{ }^{\circ} \mathrm{C}$. These two 3D-analyses were previously published in [12] by the authors. The main results are summarized in the following.

\subsection{D Electromagnetic Verification}

In Figure 6, the optimal WRSM is drawn from the optimal parameters provided in Table 3.

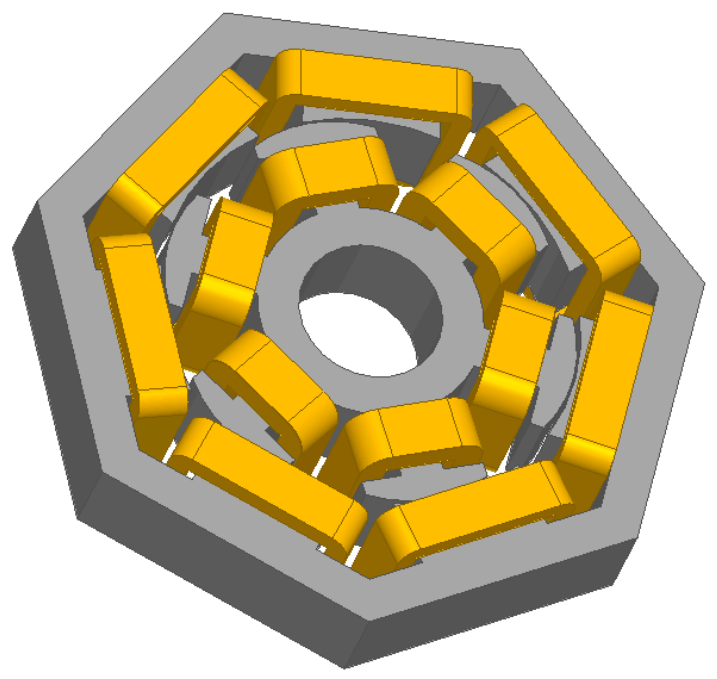

Figure 6. 3D configuration of the optimal heptagonal WRSM. 
In [12], a 3D-FE method was used to analyze the flux in the end-zone of this machine by using ANSYS Maxwell software, [18-20]. This takes $60 \mathrm{~h}$ of CPU-time to compute the magnetic induction of this machine, provided in Figure 7.
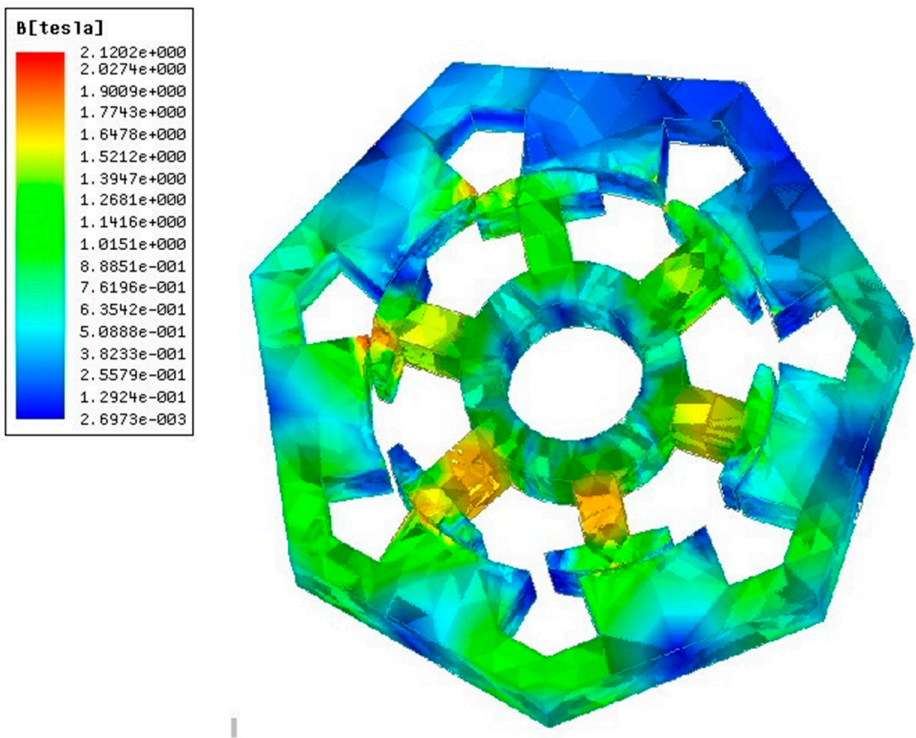

Figure 7. Magnetic induction distribution of the stator and the rotor.

In Table 5, the 3D-FE numerical simulations provided results, which are a bit different from those presented in Table 4 (obtained by 2D-FE simulations): the average torque is $4.84 \mathrm{Nm}$ and is less than $5 \mathrm{Nm}$, and the surface temperature is $95.75{ }^{\circ} \mathrm{C}$ which is a bit greater than $85^{\circ} \mathrm{C}$. That represents the main differences.

Table 5. 3D machine performance.

\begin{tabular}{ccc}
\hline Performance & Value & Unit \\
\hline Average torque & 4.84 & $\mathrm{Nm}$ \\
Torque ripple & $4.28 \%$ & \\
Phase Voltage (rms) & 91.74 & $\mathrm{~V}$ \\
Total losses & 192.28 & $\mathrm{~W}$ \\
Efficiency & $94.79 \%$ & \\
Temperature & 95.75 & ${ }^{\circ} \mathrm{C}$ \\
\hline
\end{tabular}

The surface temperature is still less than $105^{\circ} \mathrm{C}$, so the main problem is about the average torque, which is less than $5 \mathrm{Nm}$. By increasing the length of this machine and by performing other 3D-FE simulations, an average torque of $5 \mathrm{Nm}$ is reached without increasing the surface temperature (only $+0.32{ }^{\circ} \mathrm{C}$ compare to the result obtained in Table 5) too much, see Table 6 . The new value of the length is $32.65 \mathrm{~mm}$, while all the other parameters are the same, see Table 3.

Table 6. Adjusted machine performance.

\begin{tabular}{ccc}
\hline Performance & Value & Unit \\
\hline Average torque & 5 & $\mathrm{Nm}$ \\
Torque ripple & $4.05 \%$ & $\mathrm{~V}$ \\
Phase Voltage (rms) & 94.27 & $\mathrm{~W}$ \\
Stator copper losses & 35.80 & $\mathrm{~W}$ \\
Rotor copper losses & 51.51 & $\mathrm{~W}$ \\
Iron losses & 105.94 & \\
Efficiency & $94.89 \%$ & ${ }^{\circ} \mathrm{C}$ \\
Temperature & 96.07 & \\
\hline
\end{tabular}




\subsection{Thermal Analysis}

The integration of power converters on the machine housing could increase the temperature of the WRSM. Note that, if the temperature is too high, this can cause problems and thus shorten the life of the converters and the whole machine. In this study, a limit on the temperature inside the coils is fixed to $105^{\circ} \mathrm{C}$. Hence, the temperature distribution of the new corrected machine has to be determined.

The temperature can be computed following two approaches: lumped-parameter thermal analysis or numerical methods. Using lumped-parameter thermal models, this is possible to estimate some key temperatures inside an electrical machine much more quickly than numerical methods. However, the computation of the lumped parameters can be very difficult to perform for some complex geometrical parts of the WRSM [20].

On the contrary, the use of 3D numerical simulations makes it possible to predict the temperature of complex structures, but with an enormous calculation time; FE or CFD methods can be used.

FE simulations enable the computation of the temperature accurately inside solid bodies. However, in order to consider the effect of the fluid on the solid, convection heat transfer coefficients need to be applied at the boundaries between the solid zone and the moving fluid. These coefficients are provided by using analytical approaches or some experimental tests. Using CFD simulation, the solid and the fluid regions can be modeled and the machine temperature is then analyzed with a high accuracy. The exact evaluation of the temperature, at different locations inside the machine, is an extremely high CPU time consuming task because of the complicity of the fluid velocity and of the surface properties of the machine $[20,21]$. In this paper, the CFD method is selected to analyze the temperature of the WRSM without a cooling system by using ANSYS Fluent software.

The family of the Reynolds-Averaged Navier-Stokes (RANS) models has been chosen because they are widely used to consider the field of turbulence. RANS is the most widely used method for thermal analysis of electrical machines. Based on turbulent kinetic energy and dissipation rate or length scale transport equations, RANS models are commonly used for developing the turbulences arising from buoyancy, shear, or shocks.

For incompressible fluids, the density does not change with the pressure. The RANS equations can be described for fluid flow of an incompressible fluid by the following equations, see [22]:

$$
\begin{gathered}
\rho \frac{\partial U}{\partial t}+\rho(U . \nabla) U=-\nabla P+2 \nabla(\mu \nabla U)+f, \\
\nabla U=0,
\end{gathered}
$$

where $\rho$ is the density, $\mathrm{U}$ is average velocity field, $P$ is the pressure, $\mu$ is the dynamic viscosity, and $f$ is the volumetric force.

A simplified model of all the parts in the new corrected machine is created in 3D by using ANSYS-Maxwell software. The complete model is required due to the lack of symmetry in the geometry of this machine. The thermal modeling of some parts, such as winding, bearing is a challenging task. The bearing is thus not modeled in this study. In order to simplify the CFD model, some assumptions are made as follows, see [23]: - the ambient temperature is constant, - there is no influence of the temperature rise on the thermal property of materials, - the lamination is modeled as an orthotropic composite material, which has different thermal conductivities in different directions, - air is blown in and out perpendicular to the inlet and the outlet faces, - heat sources are uniformly distributed in the corresponding parts of the machine.

Since the stator and the rotor are laminated, the eddy current losses are reduced. A low thermal conductivity insulation separates the lamination. Hence, the thermal conductivity of the rotor and stator (in the axial direction) is computed as the equivalent conductivity of insulation and lamination [24]. In addition, the winding insulation is simplified and 
consists only of the copper and wire insulation. Table 7 shows the thermal properties of the different materials used.

Table 7. Thermal Properties of materials.

\begin{tabular}{cccc}
\hline Material & $\begin{array}{c}\text { Conductivity } \\
\mathbf{( W / m K )}\end{array}$ & $\begin{array}{c}\text { Capacity } \\
\mathbf{( J / k g K )}\end{array}$ & $\begin{array}{c}\text { Density } \\
\mathbf{( k g / \mathbf { m } ^ { 3 } )}\end{array}$ \\
\hline Lamination & $\begin{array}{c}\text { Radial (28) } \\
\text { Axial (2) }\end{array}$ & 420 & 7650 \\
\hline Copper & 387 & 380 & 8960 \\
Polyimide & 0.26 & 1000 & 1449 \\
Steel & 16.27 & 502.48 & 8030 \\
Aluminium & 202.4 & 871 & 2719 \\
Air & 0.026 & 1000 & 1.22 \\
\hline
\end{tabular}

Regarding the inlet and outlet regions, these are faces through which air enters and exits the simulation domain. Moreover, the inlet pressure and outlet pressure are used to define the boundary conditions of the inlet and outlet flow, respectively; zero Pascal is taken as the relative pressure of natural convection, [25]: inlet pressure is equal to $0 \mathrm{~Pa}$ with $T_{a m b}=20^{\circ} \mathrm{C}$; outlet pressure is equal to $0 \mathrm{~Pa}$ ) with $T_{a m b}=20^{\circ} \mathrm{C}$; wall of moving fluid are taken as moving wall; -Contact interfaces are taken into account as coupling surfaces.

The rotation of the WRSM owns a direct effect on the fluid flow and the pressure distribution. Two main techniques can be used in order to simulate the machine rotation: Moving Reference Frame (MRF) and Sliding Mesh (SM). Therefore, the MRF technique is used for a steady state analysis, and the SM technique is used for a transient analysis [26].

In this work, the MRF technique is used to simulate the relative motion of the rotor and stator. The fluid region is divided into two regions (inner and outer), as it is shown in Figure 8 . The internal fluid area surrounding the rotor part rotates at motor speed. The outer fluid area is stationary. The area, where the MRF technique is applied, does not move. However, all walls in the MRF region are rotated to account for the generation of a constant grid flux. The grid flux is computed from the properties of the reference frame. Hence, the forces due to rotation are introduced in the MRF region. This approach is suitable for steady-state analysis and solves for most flow behaviors, such as mass flow and pressure rise, through rotating components [27].

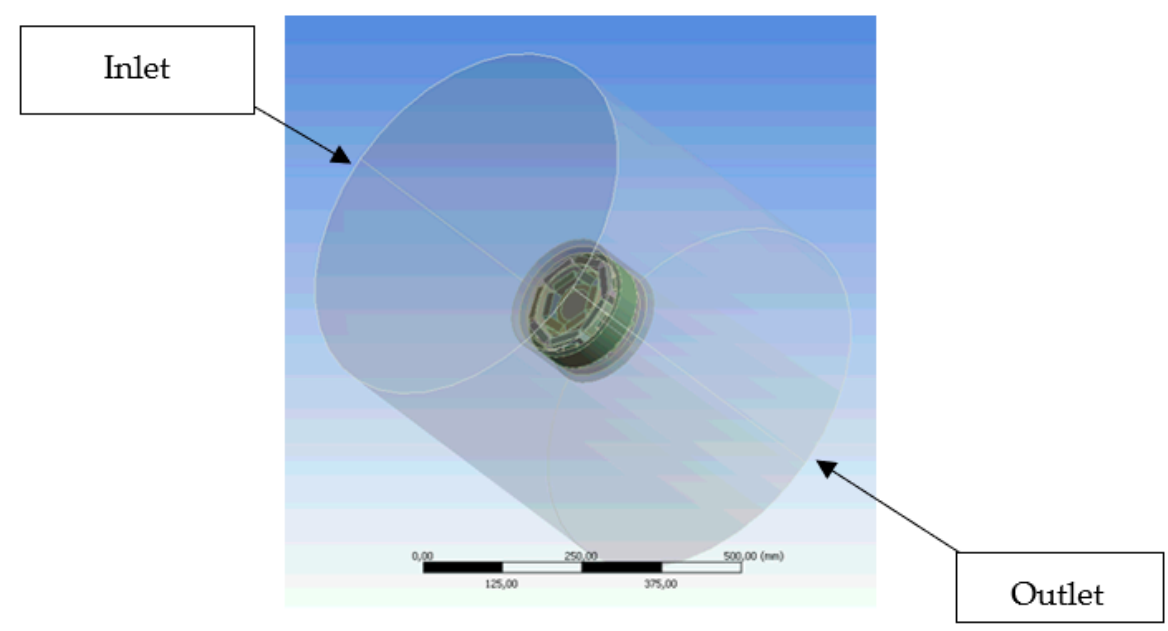

Figure 8. Inlet and outlet regions in our thermal simulation.

The k- $\varepsilon$ realizable model with Enhanced Wall Treatment is used here because of its robustness, and the resolution methods are parametrized as second order [28]. Cellular zone conditions govern the material, heat generation, and rotational properties of the solid and fluid zones. The volumetric heat production rates represent the copper and 
iron losses. In natural convection, fluid movement is provided by density differences due to temperature differences. Consequently, air is considered as an ideal incompressible gas with specific operating conditions. In order to obtain those following results, $13 \mathrm{~h}$ of CPU-time were required using a PC-server with 16 processors $(2.6 \mathrm{GHz}$ and $128 \mathrm{~GB}$ ).

Figures 9 and 10 show the temperature distribution of the WRSM. The field winding temperature $\left(113.80^{\circ} \mathrm{C}\right)$ is the maximum temperature. The surface temperature is about $104.48^{\circ} \mathrm{C}$. The difference in the surface temperature of the frame between the analytical equation of the temperature and the CFD simulation is about $8.05 \%$ (with the same losses from 3D electromagnetic simulations). Nevertheless, only natural convection is investigated in this study, and the radiation should be considered at the surface of the machine frame for electrical machines without cooling systems.

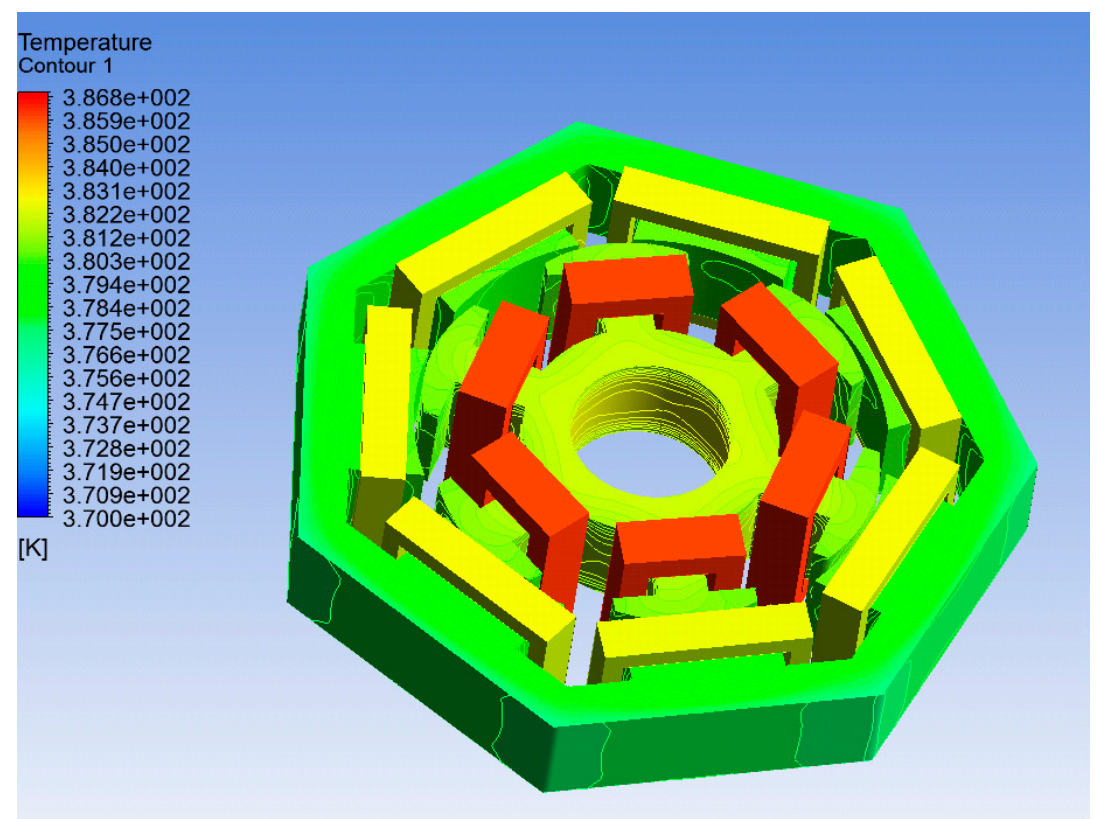

Figure 9. Temperature distribution of the WRSM from $96.85^{\circ} \mathrm{C}$ to $112.85^{\circ} \mathrm{C}$.

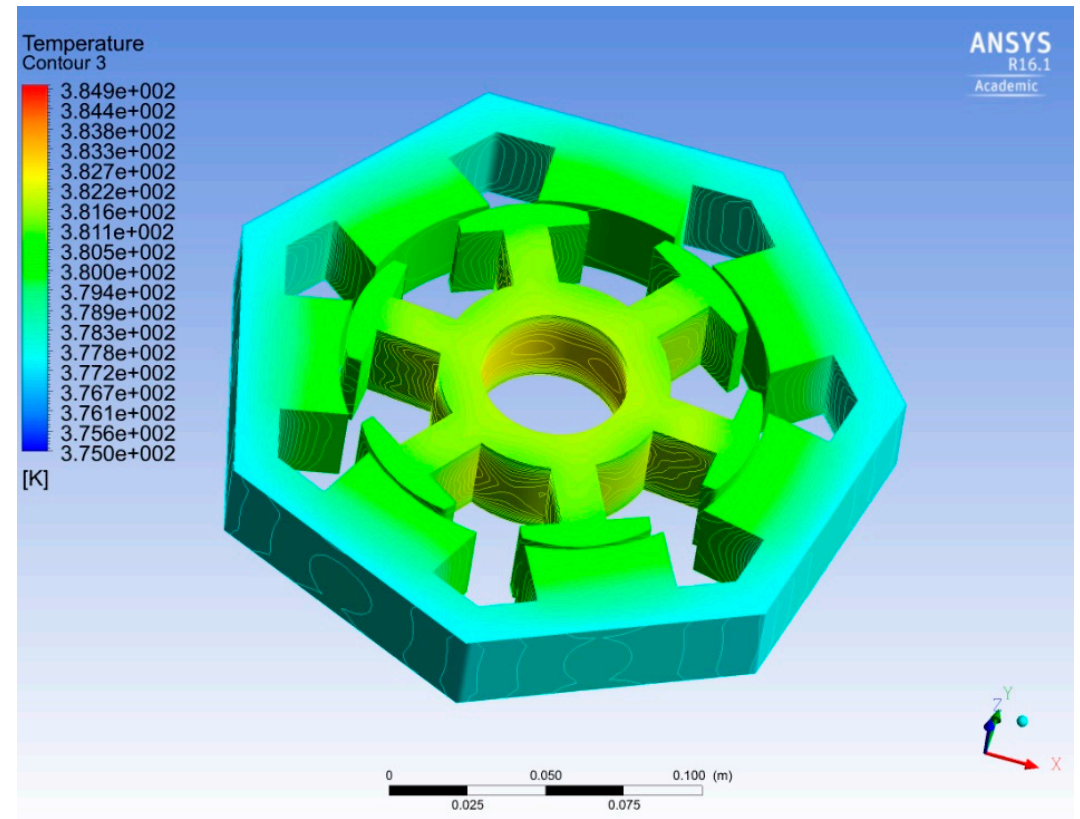

Figure 10. 'zoom' on the temperatures of the laminations from $101.85^{\circ} \mathrm{C}$ to $110.85^{\circ} \mathrm{C}$. 
Note that the limit on the coil temperature was previously fixed to $105^{\circ} \mathrm{C}$ in order to guarantee the perfect functioning of the machine. Hence, to provide that temperature at the end of this complete design methodology (see Figure A1), a limit of $85^{\circ} \mathrm{C}$ had to be set for our design problem. Hence, the coil temperature of the new corrected WSRM obtained using the CFD method, is $113.48^{\circ} \mathrm{C}$; which is a bit more than the limit $\left(+8.48^{\circ} \mathrm{C}\right)$. This should not be a problem, as some dissipation, due to the shaft and bearings of the machine, is expected and this will lower the temperature of the coils.

\section{Preliminary Experimental Test}

The prototype machine shown in Figure 11 is a WRSM with $3.67 \mathrm{~kW}, 7$ phases, 7 slots, and 6 poles, which follows the optimal dimensions given in Table 3 with a corrected length of $32.65 \mathrm{~mm}$, as explained in Section 3. With some limitations of power supply, no load characteristics and the static characteristics of the machine prototype are measured and then compared to the numerical results. In this case, we make a 3D printed plastic flange, slip rings, and brush to supply DC current for the field winding.

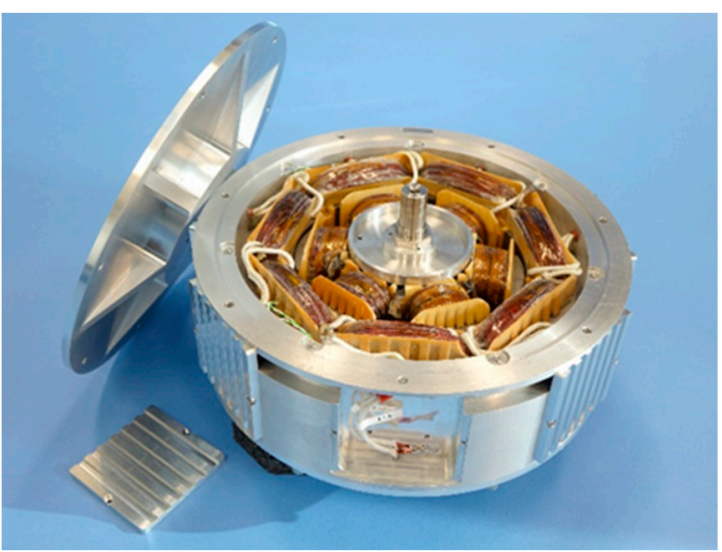

Figure 11. Machine prototype of WRSM with 7 phases, 7 slots, and 6 poles.

This section may be divided by subheadings. It should provide a concise and precise description of the experimental results, their interpretation, and the experimental conclusions that can be drawn.

\subsection{Electromotive Force at No Load}

The purpose of this initial test is to verify the machine construction and system configuration; where the prototype is in no-load operation, only set by rotor field winding, which is excited by an external DC power supply. In addition, the rotation of the rotor is clockwise and the rotational speed is about $700 \mathrm{rpm}$. The value of the excitation current which was obtained via the optimization process, is 5A. The comparison of the ElectroMotive Force (EMF) waveforms, between 3D FE simulation and this experimental test, is shown in Figure 12. Note that the measured EMF waveform is similar and very close to the simulated one. The waveform of the EMF is not perfectly sinusoidal due to the saturation of the magnetic induction. 


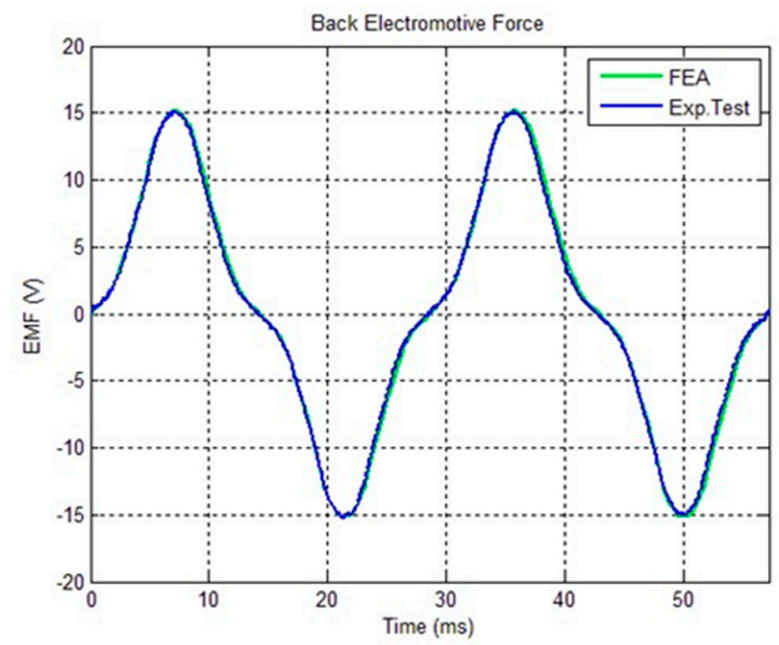

Figure 12. EMF waveform comparison between 3D FE analysis and experimental test.

\subsection{Static Torque vs. Rotor Angle}

The rotor winding and the stator winding are supplied by DC currents, as shown in Figure 13, in order to perform measurements of the static torque.

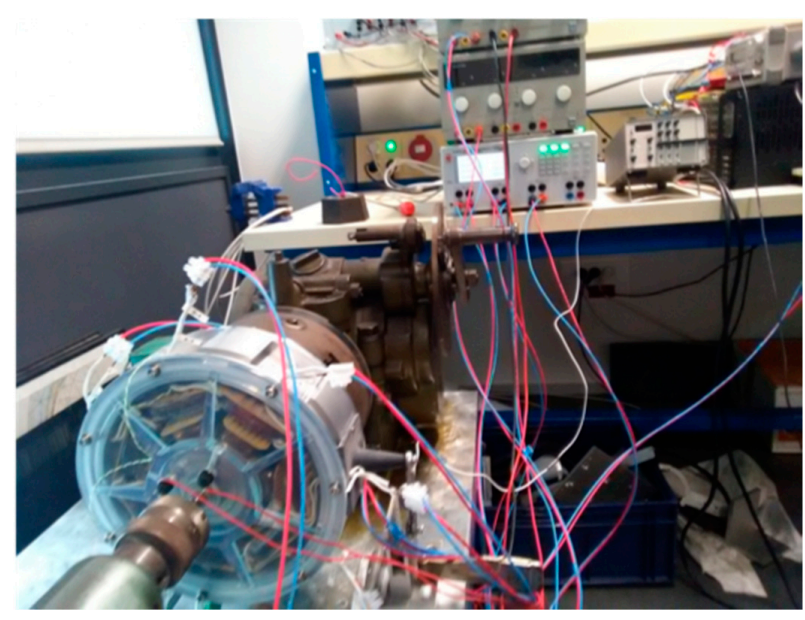

Figure 13. Set-up test band for measuring the static torque.

The rotor current is $5.10 \mathrm{~A}$, and the armature currents are fed by DC current supply sources, as shown in Table 8. The DC supplying current in each phase of the machine is computed from of a 7 phase balanced supply, as described in Table 8. The "Arms" current is fixed at $6.3 \mathrm{~A}$.

Table 8. Supplying current in each phase for the measures of the static torque.

\begin{tabular}{ccc}
\hline Phase Current & $\begin{array}{c}\text { Theoretical Value (A) } \\
\mathbf{t = 0}\end{array}$ & Measured Value (A) \\
\hline$I_{A}=I_{e f f} \sqrt{2} \cos (w t)$ & 8.87 & 8.79 \\
$I_{B}=I_{e f f} \sqrt{2} \cos \left(w t-\frac{2 \pi}{7}\right)$ & 5.53 & 5.53 \\
$I_{C}=I_{e f f} \sqrt{2} \cos \left(w t-\frac{4 \pi}{7}\right)$ & -1.97 & -1.97 \\
$I_{D}=I_{e f f} \sqrt{2} \cos \left(w t-\frac{6 \pi}{7}\right)$ & -7.99 & -7.99 \\
$I_{E}=I_{e f f} \sqrt{2} \cos \left(w t-\frac{8 \pi}{7}\right)$ & -7.99 & -7.99 \\
$I_{F}=I_{e f f} \sqrt{2} \cos \left(w t-\frac{10 \pi}{7}\right)$ & -1.97 & -1.97 \\
$I_{G}=I_{e f f} \sqrt{2} \cos \left(w t-\frac{12 \pi}{7}\right)$ & 5.53 & 5.53 \\
\hline
\end{tabular}


The maximum static torque shown in Figure 14 is 4.97 N.m. Comparing the corresponding results from a 3D-FE simulation and the real measurements on the machine prototype shows that the two maximum static torques are very close, with a relative error less than 3\%. The small differences between the simulated and measured torques can come from different values of the currents, by some variations in the construction of the prototype, and/or by the measuring process.

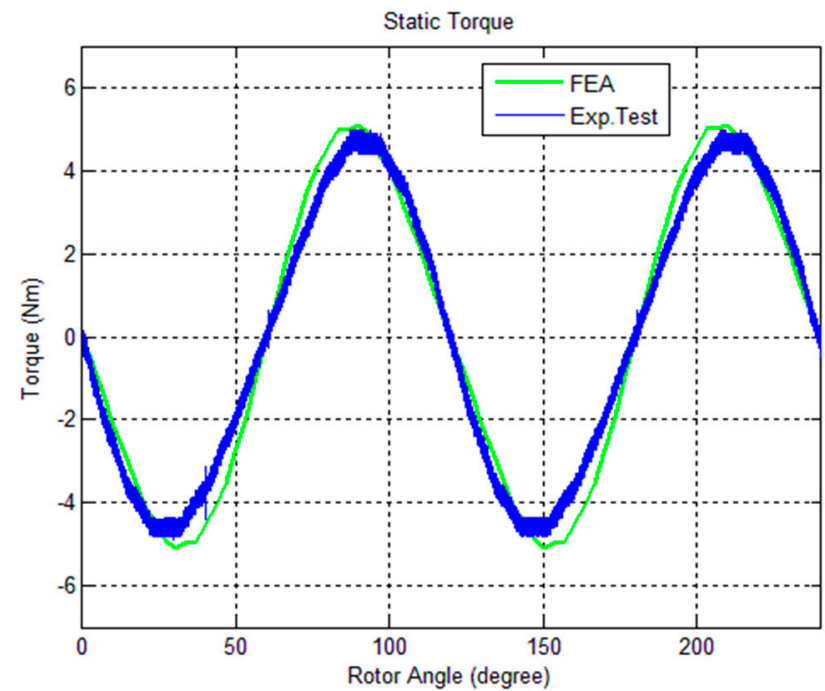

Figure 14. Static torque vs. rotor angle comparison between 3D FE analysis and experimental test.

In order to be sure that the maximum static torque is $5 \mathrm{Nm}$, with different values of the time, the static torque is measured at 11 discretized points of the power supply between the maximum current of phase $A$ to the maximum current of phase B; to make those steps, the time $t$ is changed in the equation of the armature current as follows:

$$
I_{\text {phase }_{i}}=I_{s} \cos \left(w t+(i-1) \frac{2 \pi}{7}\right)
$$

where $I_{\text {phase }_{i}}$ is the current of phase $i, I_{s}$ is the peak value of the armature current, and $w$ is the angular frequency.

In Table 9, the maximum static torques for the 11 experimental tests and 2D FE simulations are shown. From these experimental tests, we can see that all of the measured static torques correspond to the simulated ones with a very small relative error. Thus, we can conclude that the dynamic torque of the prototype corresponds to the numerical predictions.

Table 9. Static Torque with different currents.

\begin{tabular}{ccc}
\hline Steps & Experimental Test & 2D FE Analysis \\
\hline $0\left(\mathrm{I}_{\mathrm{A}} \max \right)$ & 4.97 & 5.07 \\
$\pi / 35$ & 5.13 & 5.06 \\
$2 \pi / 35$ & 5.04 & 5.08 \\
$3 \pi / 35$ & 5.16 & 5.08 \\
$4 \pi / 35$ & 4.95 & 5.03 \\
$5 \pi / 35$ & 5.06 & 5.03 \\
$6 \pi / 35$ & 5.20 & 5.06 \\
$7 \pi / 35$ & 5.11 & 5.08 \\
$8 \pi / 35$ & 5.06 & 5.08 \\
$9 \pi / 35$ & 5.10 & 5.03 \\
$10 \pi / 35\left(\mathrm{I}_{\mathrm{B}} \max \right)$ & 5.13 & 5.02 \\
\hline
\end{tabular}


Note that a link to see the fabrication of our prototype (with a heptagonal structure and optimized dimensions) and the preliminary experimental tests, is available on: https: / / www.youtube.com/watch?v=8eoO_WeAPgg (accessed on 19 October 2021) (on YouTube put keywords CWM Dominique H) (Supplementary Materials).

\section{Conclusions}

In this paper, we describe our methodology of design of a WRSM with 7 phases, 7 slots, and 6 poles, which is mainly based on an optimization process, see the left part of Figure A1. From the schedule of conditions, a non-linear and non-convex optimization problem is provided. However, in order to make it possible, the use of optimization codes, 2D-FE simulations are chosen to compute the constraints. Moreover, the limit on the temperature of the coils is replaced by a limit on the surface temperature (by using a simplified equation based on the iron losses). In this optimization phase, NOMAD derivative free software appears to be very efficient to solve our kind of design problem, but it takes days of computations. Thus, first, a relaxed optimization problem is solved quite quickly by using a few starting points and then, NOMAD provides all the associated local minima. Hence, the best local minimum is selected as a starting point to solve the original optimization problem. After 5 days of computations, NOMAD provides a local optimized design of a WRSM. Hence, this optimal solution needs to be verified by using 3D electromagnetic and $3 \mathrm{D}$ thermal analysis. The $3 \mathrm{D}$ electromagnetic validation shows that the average torque is inferior to $5 \mathrm{Nm}$, so a new corrected WSRM is obtained by just increasing the length. In addition, we observe that the iron losses obtained using 3D-FE analysis are higher than using 2D-FE simulations. Indeed, this is due to the high leakage flux in the end-winding of non-overlapping concentrated winding. Moreover, the coil temperature obtained by CFD simulations is higher, by about $8.5^{\circ} \mathrm{C}$, than the $105^{\circ} \mathrm{C}$ (the limit on the temperature of the frame). This should not be a problem because we expect to have dissipations by shaft and bearings of the machine and thus, this will decrease the temperature of the coils. Note that a prototype machine is built, and several first experimental tests are performed showing that the back-EMF at no load (700 rpm) owns a similar waveform compared to the one predicted by 3D-FE simulations. Moreover, the difference of the maximum static torque, between the 3D-FE simulations and the experimental tests, are small.

Supplementary Materials: Manufacturing and design of the prototype are available online at https:/ / www.youtube.com/watch?v=8eoO_WeAPgg (accessed on 18 October 2021).

Author Contributions: Huong Thao Le Luong did the main part of the work and she was supervised by all her other co-authors. All authors have read and agreed to the published version of the manuscript.

Funding: This research received no external funding.

Institutional Review Board Statement: Not applicable.

Informed Consent Statement: Not applicable.

Conflicts of Interest: The authors declare no conflict of interest.

\section{Appendix A}

Scheme of our Design Methodology based on:

- Optimization,

- 3D Numerical Validations,

- Preliminary Experimental Tests on a Prototype. 


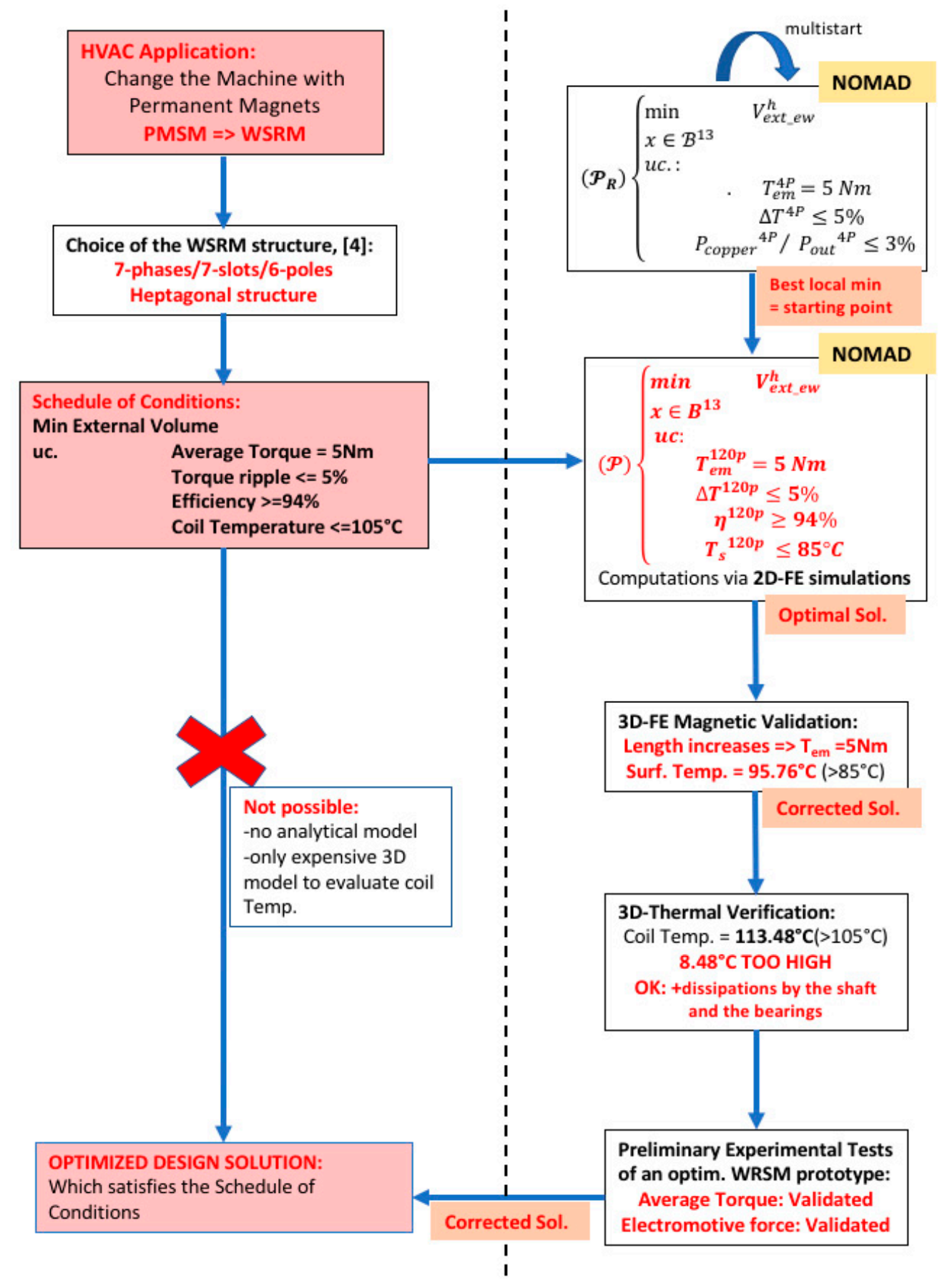

Figure A1. Methodology of a WSRM Design.

\section{References}

1. Rossi, C.; Casadei, D.; Pilati, A.; Marano, M. Wound Rotor Salient Pole Synchronous Machine Drive for Electric Traction. In Proceedings of the Industry Applications Conference, 41st IAS Annual Meeting, Tampa, FL, USA, 8-12 October 2006. Conference Record of the IEEE.

2. Jürgens, J.; Brune, A.; Ponick, B. Electromagnetic Design and Analysis of a Salient Pole Synchronous Machine with Tooth-Coil Windings for Use as a Wheel Hub Motor in an Electric Vehicle. In Proceedings of the Electrical Machines (ICEM) Conference, Berlin, Germany, 2-5 September 2014.

3. Liu, H.; Xu, L.; Shangguan, M. Finite element Method Simulation of a High Speed Wound Rotor Synchronous Machine. In Proceedings of the Electrical Machines and Systems (ICEMS) Conference, Beijing, China, 20-23 August 2011. 
4. Gündogdu, T.; Kömügöz, G. Implementation of Fractional Slot Concentrated Winding Technique in Large Salient-Pole Synchronous Generators. In Proceedings of the Power Electronics and Machines in Wind Applications (PEMWA), Denver, CO, USA, 16-18 July 2012.

5. Topaloglu, I.; Ocak, C.; Tarimer, I. A case study of Getting Performance Characteristics of a Salient Pole Synchronous Hydro Generators. Elektron. Elektrotechnika 2010, 97, 57-61.

6. Lin, D.; Zhou, P.; He, B.; Lambert, N. Steady state and transient parameter computation for wound field synchronous machines. In Proceedings of the Electrical Machines (ICEM) Conference, Marseille, France, 2-5 September 2012.

7. Shipurkar, U.; Polinder, H.; Ferreira, J.A. Modularity in Wind Turbine Generator Systems-Opportunities and Challenges. In Proceedings of the 18 Europen Conference on Power Electronics and Application, Karlsruhe, Germany, 5-9 September 2016. [CrossRef]

8. Li, G.; Zhu, Z.; Foster, P.; Stone, D.; Zhan, H. Modular Permanent-Magnet Machines with Alternate Teeth Having Tooth Tips. IEEE Trans. Ind. Electron. 2015, 62, 6120-6130. [CrossRef]

9. Motor Technologies for Industry and Daily Life Edition; Mitsubishi Electric Advance, September 2003; Volume 103. Available online: https:/ / www.advance.mitsubishielectric.com/advance/pdf/2003/vol103.pdf (accessed on 18 October 2021).

10. The Current Status of and Future Trends in Heat Pump Technologies with Natural Refrigerants. Available online: http: //www.mitsubishielectric.com/en/about/rd/advance/pdf/vol120/vol120.pdf (accessed on 18 October 2021).

11. Le Luong, H.T.; Hénaux, C.; Messine, F.; Bueno-Mariani, G.; Voyer, N.; Mollov, S. Finite Element Analysis of a modular brushless wound rotor synchronous machine. In Proceedings of the 9th International Conference on Power Electronics, Machines and Drives, Liverpool, UK, 17-19 April 2018.

12. Le Luong, H.T.; Messine, F.; Henaux, C.; Mariani, G.B.; Voyer, N.; Mollov, S. 3D Electromagnetic and Thermal Analysis for an Optimized Wound Rotor Synchronous Machine. In Proceedings of the 2018 XIII International Conference on Electrical Machines (ICEM), Alexandroupoli, Greece, 3-6 September 2018; pp. 455-460. [CrossRef]

13. Liu, H.; Xu, L.; Shangguan, M.; Fu, W.N. Finite Element Analysis of 1 MW High Speed Wound-Rotor Synchronous Machine. IEEE Trans. Magn. 2012, 48, 4650-4653. [CrossRef]

14. Le Digabel, S. Blackbox optimization with the NOMAD software, GERAD and Ecole Polytechnique de Montréal (MAGI), CanmetEnergie. ACM Trans. Math. Softw. 2015, 37, 1-15. [CrossRef]

15. Audet, C.; Custodio, A.L.; Dennis, J.E., Jr. Erratum, Mesh adaptive direct search algorithms for constrained optimization. SIAM J. Optim. 2018, 18, 1501-1503. [CrossRef]

16. Seo, M.; Lee, T.; Kim, J.; Kim, Y.; Jung, S. Principal Component Optimization with Mesh Adaptive Direct Search for Optimal Design of IPMSM. IEEE Trans. Magn. 2017, 53, 8105604. [CrossRef]

17. Le Luong, H.T.; Messine, F.; Henaux, C.; Mariani, G.B.; Voyer, N.; Mollov, S. Comparison between fmincon and NOMAD Optimization Codes to Design Wound Rotor Synchronous Machines. Int. J. Appl. Electromagn. Mech. 2019, 60, S87-S100. [CrossRef]

18. ANSYS Maxwell 2D/3D User's Guide. Available online: http:/ / ansoft-maxwell.narod.ru/english.html (accessed on 18 October 2021).

19. Pyrhönen, J.; Jokinen, T.; Hrabovcova, V. Design of Rotating Electrical Machines; John Wiley \& Sons, Ltd.: Hoboken, NJ, USA, 2008; ISBN 978-0-470-69516-6.

20. Yeo, H.-K.; Park, H.-J.; Jung, S.-Y.; Ro, J.-S.; Jung, H.-K.; Seo, J.M. Electromagnetic and thermal analysis of a surface-mounted permanent-magnet motor with overhang structure. IEEE Trans. Magn. 2017, 53, 1-4. [CrossRef]

21. Pechanek, R.; Kindl, V.; Skala, B. Transient thermal analysis of small squirrel cage motor through coupled FEA. Sci. J. 2015, 560-563. [CrossRef]

22. Pechanek, R.; Bouzek, L. Analyzing of two types water cooling electric motors using computational fluid dynamics. In Proceedings of the 15th International Power Electronics and Motion Control Conference and Exposition, Novi Sad, Serbia, 4-6 September 2012.

23. Fan, X.; Qu, R.; Li, J.; Li, D.; Zhang, B.; Wang, C. Ventilation and Thermal Improvement of Radial Forced Air-Cooled FSCW Permanent Magnet Synchronous Wind Generators. IEEE Trans. Ind. Appl. 2017, 53, 3447-3456. [CrossRef]

24. Polikarpova, M. Liquid Cooling Solutions for Rotating Permanent Magnet Synchronous Machines. Ph.D. Thesis, Science at Lappeenranta University of Technology, Lappeenranta, Finland, 21 November 2014.

25. Ding, S.; Li, H. Investigation of characteristics of fluid flow pattern for air-cooled motor. In Proceedings of the 2016 IEEE 11 th Conference on Industrial Electronics and Applications (ICIEA), Hefei, China, 5-7 June 2016; pp. 2044-2048. [CrossRef]

26. Connor, P.H.; Pickering, S.J.; Gerada, C.; Eastwick, C.N.; Micallef, C.; Tighe, C. Computational fluid dynamics modelling of an entire synchronous generator for improved thermal management. IET Electr. Power Appl. 2013, 7, 231-236. [CrossRef]

27. Connor, P.; Pickering, S.; Gerada, C.; Eastwick, C.; Micallef, C. CFD modelling of an entire synchronous generator for improved thermal management. In Proceedings of the 6th IET International Conference on Power Electronics, Machines and Drives (PEMD 2012), Bristol, UK, 27-29 March 2012. [CrossRef]

28. SanAndres, U.; Almandoz, G.; Poza, J.; Ugalde, G. Design of Cooling Systems Using Computational Fluid Dynamics and Analytical Thermal Models. IEEE Trans. Ind. Electron. 2013, 61, 4383-4391. [CrossRef] 